\title{
Exploration of " $2+2$ " Cooperation in Cultivating Pelagic Fisheries Talents
}

\author{
Hai-long $\mathrm{XU}^{1,2,3}$, Dong-qing $B A I^{1,2,3, \star}$, Xiao-rong $\mathrm{ZOU}^{4}$ \\ Wei-guo QIAN ${ }^{4}$ and Xiu-ting QIAO ${ }^{1,2,3}$ \\ ${ }^{1}$ College of Fishery, Tianjin Agricultural University, Tianjin, China \\ ${ }^{2}$ National Demonstration Center for Experimental Aqua-Ecology and Aquaculture Education \\ Tianjin Agriculture University, China \\ ${ }^{3}$ Tianjin Key Laboratory of Aqua-Ecology and Aquaculture, Tianjin, China \\ ${ }^{4}$ College of Marine Sciences, Shanghai Ocean University, Shanghai, China \\ ${ }^{*}$ Corresponding author
}

Keywords: Pelagic Fisheries; Training Talents; Interschool Cooperation.

\begin{abstract}
One of the goals of higher education is to service the civil economic development. In order to play full roles of Tianjin Agricultural University in developing the fishery for Tianjin civil economy, the project of " $2+2$ " cooperation in cultivating pelagic fisheries talents was carried out by Tianjin Agricultural University and Shanghai Ocean University. In the paper, the background, training plan, school registration management, evaluation of scholarship, and security management and so on were introduced to give an experience for talent training in marine fishery science and technology in detail.
\end{abstract}

\section{Development Status of China's Pelagic Fisheries}

China is a traditional big agricultural country, marine fisheries play an important role in the civilian economy development, and it is an important part of modern agriculture and marine economy. Marine fisheries are of great significance to increase the fishermen's income, to increase the chance for labor employment, to promote coastal economic development, and to protect maritime rights. Marine fisheries developed rapidly after the founding of the People's Republic of China, that it solved the problem of effective supply of aquatic products of China market successfully, and made China become a fishing powerful country, aquatic product exporter and important pelagic fisheries country all our the world, the total output of aquatic products ranks the first in the world for more than 20 years.

In the 1980s, fishermen faced some difficult situations such as reduced fishing production and decreased rapidly in fishery revenue with the increasing fishing effort, environmental pollution, offshore fishery resources declined, in order to adapt to the new fishery environment and increase the influence and voice of international marine resources utilization, the Chinese government encouraged and supported the development of pelagic fisheries.

The first distant fishing fleet of China was constructed, and it has 12 trawlers and a refrigerated transport vessel came from Yantai, Zhoushan, Fujian and Zhanjiang province, and these vessels departed from Mawei Port on March 10, 1985, passed through the South China Sea and the Straits of Malacca, crossed the Indian Ocean, passed through the Red Sea and the Suez Canal, got into the Mediterranean Sea, crossed the Strait of Gibraltar, arrived in Senegal, Carr Harbor in West Africa along the Atlantic Ocean, lasted 54 days and nights, that unveiled the prelude of China pelagic fisheries.

After more than 30 years of development, China has become one of the most important pelagic fisheries countries in the world [1], by 2016, the available data show that there are 2,571 pelagic fishing vessels in China, with a total output of about 2 million tons. The fishing ground covered the exclusive economic zones in over 40 countries and regions, as well as the Pacific Ocean, Indian Ocean, Atlantic high seas and the Southern Ocean. Although the scale of China's pelagic fisheries 
industry has entered the forefront of the world, the pelagic fisheries still fails to get rid of the predicament of "large but not strong", there are still some gaps between China and other pelagic fisheries powers in the technical level of pelagic fisheries equipment and fishing exploration, the education level of employees and the management level [2-3].

Education of marine fisheries in China can be traced back to the Fishing Department of Jiangsu Provincial Fisheries School when it was established in 1912, and the names of specialty have experienced "Fishing science", "Marine Fishing", "Industrial Fishing", "Marine Fisheries" one by one. In 1997, the claim of merging major catalogs was raised by the State Education Commission, the "Marine Fisheries" and the "Fishery Resources and Fisheries Administration Major" was integrated to form the "Marine Fishery Science and Technology Major". At present, there are 10 colleges or universities set up major of Marine Fishery Science and Technology in China, included Shanghai Ocean University, Ocean University of China, Dalian Ocean University, Zhejiang Ocean University, Jimei University, Tianjin Agricultural University Guangdong Ocean University, Hebei Agricultural University, Yantai University and Qiongzhou College [4]. Due to differences in history of running schools, the teaching staff and the goal of training talents, there are some differences in the major direction and curriculum of each school [5].

\section{Development Status of Marine Fishery Science and Technology Major in Tianjin Agricultural University}

In 1999, the construction of "coastal urban agriculture" was proposed in Tianjin. Then Tianjin Agricultural University put forward to establish the major of Marine Fishery Science and Technology for meeting the needs of urban agriculture and civil economic and social development, revolving around the requirements for talents in the environmental protection, restorative marine resources and water environment in the development of the Bohai Rim Economic Circle, and promoting continually the contribution of marine fisheries to local economic development based on the unique geographical location and development characteristics of Tianjin. After the Ministry of Education and the Tianjin Education Committee approved in 2002, the major of Marine Fishery Science and Technology in Tianjin Agricultural University enrollment began in 2003, and after four year's study, the undergraduates were given the bachelor's degree of agronomy when they graduated.

In the process of construction, development and talent cultivation, marine fishery science and technology major of Tianjin Agricultural placed emphasize on the training of interdisciplinary knowledge, ability and quality, perfecting of fishing gear theory and fishing method combined with the rules and characteristics of fish behavior, expanding the direction of fishery informatization and digitalization research and development by means of computer and information technology based on knowledge of oceanography, carrying out the research about the fishery resources biology, environmental science and management, and fishery stock assessment, optimizing the fishing strategy and changing the fishery management concept, to realized "responsible" fisheries utilization and management.

\section{Development Status of Pelagic Fisheries College Shanghai Ocean University}

In 1995, the State Education Commission launched the "reform and practice of undergraduate teaching in twenty-first Century", and Shanghai Aquaculture University utilized the opportunity of responsible for the "Research on Undergraduate Specialty Setting in Aquaculture" which is the sub-project of "Reform and Practice of Undergraduate Teaching in Colleges and Universities Facing the 21st Century", concerned on strategy of developing China pelagic fisheries, to adjusted the training goal and curriculum setting of major. And the teachers and students were asked to participate in the productive activities of China pelagic fishery fleet, and to carry out investigation and research on the fishery resources. All the works above mentioned, that made positive explorations for training talents in pelagic fisheries.

In order to adapt to the modern pelagic fisheries development, the Pelagic Fisheries College was 
established cooperatively by Shanghai Ocean University, Pelagic Fisheries Association of China, China Aquatic Company Limited, and Shanghai Aquatic Products (Group) Corporation in 2012, and the first year students were enrolled in the same year. Pelagic Fisheries College is a special college which is funded by enterprises and universities, managed by a council which composed of government, enterprises, schools and associations, faced the society with a new pattern, and trained badly-needed practical persons for distant fisheries enterprises and units. The complex and practical talents, who had an intimate knowledge of pelagic fisheries operation and management, mastered pelagic fisheries production technology and professional skills in operations, grasped basic knowledge and abilities about production, processing and sales of pelagic fisheries enterprises, and adapted to posts such as vessels of pelagic fisheries driving, fisheries production, vessels maintenance and enterprise management, were trained. By the end of December 2016, there are five years graduates and two years postgraduates in Pelagic Fisheries College, and 37 graduates and 8 postgraduates entered into pelagic fisheries enterprises, and they account for about $35.6 \%$ and $22.6 \%$ of the total graduates and postgraduates, respectively.

\section{Proposal of " $2+2$ " Cooperation in Cultivating}

Pelagic fisheries in Tianjin started relatively late, after 2008, pelagic fisheries were developed rapidly, from 2011 to 2014, and the output increased rapidly at an annual rate of $35.3 \%$, especially from 2013 to 2014, the increase rate reached 51.7\%. However, the lag in the cultivation talents of pelagic fisheries is not in conformity with the development of the pelagic fisheries, which severely limited the development of the pelagic fishing industry. Marine fishery science and technology major in Tianjin Agricultural University is the construction of brand specialty of Tianjin General Colleges and Universities, and persist in the talents cultivation mechanism of "a combination of government, production, study and research". In order to serve the development of pelagic fisheries and local economic development better in Tianjin, and under the premise of taking full consideration on the cost of running a school that is too high when added the direction of pelagic fisheries in marine fishery science and technology major, we proposed " $2+2$ " pattern to train talents in pelagic fisheries direction by cooperating fishery collage in Tianjin Agricultural University with College of Pelagic Fisheries in Shanghai Ocean University. The students completed the first and second grades in marine fishery science and technology major in Tianjin Agricultural University, and then completed the third and fourth grades at the College of Pelagic Fisheries of Shanghai Ocean University.

\section{Credits Recognition of " $2+2$ " Cooperation in Cultivating}

Realization of curriculum connection and credits recognition are the basis for implementing intercollegiate cooperative training talents. The orientation of pelagic fisheries in the College of Pelagic Fishery of Shanghai Ocean University is one of the directions of the majority of ocean fishery science and technology, and the curriculum still belongs to the curriculum system of marine fishery science and technology major. Although there are differences in the curriculum of marine fishery science and technology between schools, yet based on the standard (discussion draft) of Aquatic major (marine fishery science and technology) for undergraduates in 2014 (which has been formally published in 2018 through the National Standard for Teaching Quality of Undergraduate Specialty), and the compulsory contents, included basic courses, professional courses, experimental teaching, practice teaching, social practice and graduation thesis (design) of marine fisheries science and technology major in 10 universities or college in China, are the same, and also the total credits and the corresponding relationship between class hours and credits for graduation are stated clearly in this standard. Therefore, this standard provided the possibility for realizing the curriculum connection and credits recognition in cooperatively interschool for training talents of pelagic fisheries. Under the following principle, including the similar course and the equivalent total credits, and based on the cultivation plan of marine fishery science and technology major in Tianjin Agricultural University and pelagic fisheries talents training program in College of Pelagic 
Fisheries Shanghai Ocean University, we developed a new learning program for joint cultivation undergraduate students

\section{Student Management of " $2+2$ " Cooperation in Cultivating}

Works of cooperative training talents also involved student management, included student status, grants assessment, safety and so on. Talents in the direction of pelagic fisheries, who are cooperative trained by Tianjin Agricultural University and Shanghai Ocean University, are enrolled uniformly by Tianjin Agricultural University, so the students status belong to Tianjin Agricultural University, and the Graduation Certificate and Degree Certificate are awarded by Tianjin Agricultural University to them who all the achievements are qualified. During the cooperative training period in Shanghai Ocean University, students enjoy the qualification of grants assessment of Tianjin Agricultural University and the qualification of scholarship (setting by a board of trustees) of College of Pelagic Fisheries Shanghai Ocean University. During this period, students should abide by the regulations of Shanghai Ocean University, as well as Tianjin Agricultural University.

\section{Practice of "2+2" Cooperation in Cultivating}

After a series of preliminary preparations, the project of cooperation in cultivating pelagic fisheries talents was carried out by Tianjin Agricultural University and Shanghai Ocean University in 2017, and 2-4 students were selected who completed the second year courses in marine fisheries science and technology major in Tianjin Agriculture University to go to study in College of Pelagic Fisheries Shanghai Ocean University each year. Two students have participated in the cooperative training program in 2017 after voluntary application and school selection; in September 2018, another two students will go to Shanghai to study in the direction of pelagic fisheries.

\section{Summary}

To promote the development of national pelagic fisheries, the cooperation between Tianjin Agricultural University and Shanghai Ocean University in training talents in the direction of pelagic fisheries was carried out. Development of " $2+2$ " cooperation in cultivating, that will help to realize the sharing of high-quality teaching resources, improving the quality of higher personnel training, enhancing the quality of pelagic fisheries practitioners in China, strengthening the development of education and service industries, and promoting civil economic construction. At the same time, developing pelagic fisheries is one of the important ways of transformation of marine fisheries in China, and is an important form of utilizing international marine resources, and also plays an important role in promoting increasing international influence of China on the marine field and the discourse right of international ocean resources utilization.

\section{Acknowledgement}

This research was financially supported by the important project for the education reform of Tianjin Agricultural University (2017-B-02).

\section{References}

[1] Heng Zhang, Fenghua Tang, Jiahua Cheng, et al. Current status and the development thinking of ocean fishery in China [J]. Chinese Fisheries Economics, 2015, 33 (5): 16-22.

[2] Chen Wan. Enhancing the comprehensive strength and international competitiveness of Pelagic Fisheries [N]. China Fisheries newspaper, 2012-11-19 (1).

[3] Liming Liu. Cultivating application talents in pelagic fisheries [N]. China Fisheries newspaper, 2013-10-14 (A01). 
[4] Hailong Xu, Li Li, Feiyue Li, et al. Construction of Practice Teaching System for marine fishery science and technology [J]. Science and Technology Innovation Herald, 2013 (21): 167-168.

[5] Manchang Sun, Hong Yang, Liuxiong Xu. Teaching reform and practice of marine fishery science and technology major [J]. Higher Agricultural Education, 2004 (9): 52-54. 